\title{
Dignity Therapy for Adults with Cancer Receiving Palliative Care: A Case Report
}

\author{
Amanda Valério Espíndola ${ }^{1}$ \\ Ciomara Ribeiro Silva Benincá \\ Silvana Alba Scortegagna \\ Ana Caroline Secco \\ Ana Paula Monteiro Abreu \\ Programa de Residência Multiprofissional em Atenção ao Câncer da Universidade \\ de Passo Fundo, Secretaria Municipal de Saúde de Passo Fundo e Hospital da Cidade \\ de Passo Fundo, Passo Fundo, RS, Brazil
}

\begin{abstract}
This study describes the efficacy of the dignity therapy intervention with a 52 year old cancer patient undergoing palliative care. The aim of the work was to evaluate the efficacy of the dignity therapy. This is a case study, developed in fourteen meetings, before and after which the following instruments were used: Beck Anxiety Inventory, Beck Depression Inventory, Patient Dignity Inventory. Qualitative data analysis was performed, with the establishment of thematic categories. It was observed that, after the completion of the intervention, there was a reduction in the level of depression (40 to 29 points) and improvement in the sense of dignity of the patient (104 to 76 points), although there was an increase in the level of anxiety (46 to 53 points). It was highlighted that the Dignity Therapy technique favored the recovery of positive memories, the possibility to repent and ask for forgiveness and the proximity of the family members at the end of life. This was represented in the legacy document, provided by the Dignity Therapy technique, and it was concluded that the Dignity Therapy was effective.
\end{abstract}

Keywords: Dignity Therapy, palliative care, Hospital Psychology, Psycho-Oncology.

\section{Terapia da Dignidade para Adultos com Câncer em Cuidados Paliativos: Um Relato de Caso}

\section{Resumo}

Este estudo descreve a eficácia da intervenção Terapia da Dignidade, com uma paciente de 52 anos com câncer em cuidados paliativos. O objetivo do trabalho é avaliar a eficácia da terapia da dignidade. Trata-se de um estudo de caso, desenvolvido em quatorze encontros, antes e depois dos quais foram utilizados os seguintes instrumentos: Escala Beck de Ansiedade, Escala Beck de Depressão, Inventário de Dignidade do Paciente. A análise dos dados foi feita qualitativamente, pelo estabelecimento de categorias temáticas e, pela comparação dos resultados das Escalas e do Inventário. Observou-se que, após a realização da intervenção, houve redução nos níveis de depressão (40 para 29 pontos) e melhora no senso de dignidade da paciente (104 para 76 pontos), embora tenha havido aumento nos níveis de ansiedade (46 para 53 pontos). Além disso, aponta-se que a técnica Terapia da Dignidade favoreceu a

Mailing address: Universidade de Passo Fundo, Instituto de Filosofia e Ciências Humanas, Curso de Psicologia, BR 285 Campus I, São José, Passo Fundo, RS, Brazil 99001-970. Phone: (54) 3316-8330. E-mail: amndvesp@ gmail.com 
recuperação de memórias positivas, a possibilidade de arrepender-se e pedir perdão e a aproximação dos familiares no final da vida, representado no documento legado, previsto pela técnica da Terapia da Dignidade, concluindo-se que a Terapia da Dignidade foi eficaz.

Palavras-chave: Terapia da Dignidade, cuidados paliativos, Psicologia Hospitalar, Psico-Oncologia.

\section{Terapia de la Dignidad para adultos con cáncer en Cuidados Paliativos: Reporte de un Caso}

\section{Resumen}

Este estudio describe una intervención desarrollada con una paciente adulta con cáncer, de 52 años, recibiendo cuidados paliativos. Fue utilizada como técnica de intervención la Terapia de la Dignidad. El objetivo es evaluar la eficacia de la Terapia de la Dignidad. Es un estudio de caso desarrollado en catorce encuentros, que se utilizó las siguientes herramientas y técnicas: Inventario de Ansiedad de Beck; Inventario de Depresión de Beck; Inventario de la Dignidad del Paciente y la técnica Terapia de la Dignidad. Para el análisis de los datos, se utilizó el enfoque por categoría. Se observó que, después de la intervención, hubo una reducción en los niveles de depresión (40 para 29 puntos), mejora del sentido de dignidad (104 para 76 puntos) de la paciente y aumento de los niveles de ansiedad (46 para 53 puntos). Aparte de eso, se señala que la técnica Terapia de la Dignidad favoreció la recuperación de recuerdos positivos, la posibilidad de arrepentirse y pedir perdón y la conexión de la paciente con su familia y otros queridos al final de la vida, por medio de la construcción del documento legado previsto por la técnica Terapia de la Dignidad.

Palabras clave: Terapia de la Dignidad, cuidados paliativos, Psicología Hospitalaria, Psicooncología.

In 1990, the World Health Organization (WHO) established palliative care as a care mode and in 2002 defined palliative care as an approach that seeks to improve the quality of life of patients and their family members, whose diagnoses correspond to potentially life threatening diseases - such as malignant neoplasms - through the prevention and relief of suffering, pain and other physical, psychosocial and spiritual problems.

According to the WHO (2002), palliative care should be offered to all patients who are affected by serious, chronic or incurable diseases, as all of these carry a risk of death. Unlike that suggested by the social imaginary, palliative care must occur in parallel with standard care (in the case of oncology this refers to treatments such as chemotherapy, radiotherapy and surgery), which are losing ground as they are no longer effective in controlling the pathologies.

This area of care, of assistance in the process of death and dying, seeks, through analgesia, the control of symptoms, psychosocial and spiritual support, an improved quality of life for patients and their family members. The therapeutic target, therefore, is focused on the individual, not the illness, aiming to allow a dignified death (Araújo \& Silva, 2012).

Oncologic patients receiving palliative care display some common characteristics: many of these patients may be affected by severe pain, respiratory distress, nausea, lack of appetite and serious emotional and spiritual suffering, as they are in a period of anguish faced with the limitation of the treatments and the possibility of death (Araújo, Araújo, Souto, \& Oliveira, 2009).

In an article that made a literature review of psychotherapeutic interventions in palliative care, Melo, Valero and Menezes (2013) identified that the practices of psychologists should aim to understand and confront the finitude of those individuals who face processes of serious illness. Through interventions that facilitate dialogue between patient, family members and the healthcare team, it is sought to promote space for acceptance of the life lived, to evaluate the social 
and family support, to enable goodbyes and recognitions. The authors also understand that the bonds that patients make with health professionals in this period of life are intense, due to the time spent in health institutions and, especially, due to the illness, as this corresponds to a situation of losses and crises. Psychologists who work with these patients can use this strong connection in order to promote quality of life, reduce suffering and help to control anxiety and depression.

Given the complexity involved in patients undergoing palliative care, a new f psychotherapeutic model was proposed, directed toward those patients in the process of the end of life, called Dignity Therapy (Chochinov, Hack, Hassard, Kristjanson, McClement, \& Harlos, 2005). From the recognition of stressors to which a patient is submitted at the end of life (Chochinov, Hack, Hassard, Kristjanson, McClement, \& Harlos, 2002), corresponding to depression, anxiety, desire for death, hopelessness, feelings of worthlessness, helplessness, a brief psychotherapy model was organized that suggests that patients relate issues and questions for which they would like to be remembered. The therapy consists of the recording and transcription of the sessions, which make up at the end of the intervention, a document that can be delivered to a family member or other person significant to the patient.

For Chochinov et al. (2005), it was evident that most of the patients at the end of life undergo physical, spiritual, psychosocial and existential suffering. According to the authors, this suffering would be the opposite of dignified terminality. Furthermore, according to Julião (2014), dignity relates to the condition of existence as a human being, to the interpersonal relationships that the human establishes with others and to the construction of a subjective and unique narrative of his/her life. Based on these concepts of dignity, it can be comprehended why the brief psychotherapy directed towards subjects close to their finitude was named dignity therapy.

According to Fitchett, Emmanuel, Handzo, Boyken and Wilie (2015), dignity therapy is an intervention targeted toward patients with serious diseases, which focuses on aspects, such as preservation and resolution of interpersonal relationships, the sharing of loving words and the construction of a legacy document for the family and other loved ones of these patients. This technique originated from a study of cancer patients receiving palliative care in Canadian health centers. On this occasion, it was found that patients with an intact sense of dignity had no desire for an early death or a wish for death, and lower rates of depression, hopelessness and anxiety (Chochinov et al., 2002). Regarding the concept of dignity, Chochinov (2007) suggests that this is associated with how the patients perceives themselves faced with the illness and related suffering.

From this, dignity therapy emerges as an intervention that aims to provide a dignified end of life. This approach refers to a type of brief psychotherapy, directed towards patients in palliative care. For the development of the therapy, three or four meetings, held over a period of approximately two to three weeks, are required. At first, it is explained to the participant how the meetings will take place and the protocol of the dignity therapy questions is delivered. At the second meeting, the questions of the protocol are put to the participant, with the entire meeting recorded for later transcription of the content. This protocol consists of semi-structured questions, from which the answers of the patients make up, at the end of transcription, a document called the "legacy" that, in a third meeting, will be read and analyzed by the patient, with modifications made as deemed necessary. If it is not possible to complete the document in three sessions, there will be a fourth meeting to conclude the therapy. At the end of the technique, the legacy is delivered to the patient, who will decide the destination of the document: it can be given to family members and other loved ones, saved or ignored.

In addition to Canada, other countries with specific palliative care centers also utilize dignity therapy, as is the case of Portugal. In this country, Julião (2014) developed a cohort study comparing survival in patients who received dignity therapy in addition to standard palliative care, versus patients who received only the latter. This author found higher survival rates, with quality, in those patients who received the 
two approaches, namely standard palliative care and dignity therapy. It is suggested that the relationship between increased survival with quality and dignity therapy is justified by the increase in motivation and will to live, decrease in physical suffering and improvements in the nutritional and endocrine parameters. It is understood, therefore, that dignity therapy is complementary to standard palliative care, considering that other procedures to control the pain and the physical and psychosocial suffering of patients in palliative care are needed. That is, the therapy does not eliminate the therapeutic effect of other psychotherapeutic approaches in palliative treatment, these being considered integrated in the process.

It is understood, therefore, that dignity therapy arises as a tool to provide patients at the end of life with a dignified and active death. It allows the subjects to put and position themselves in relation to the issues of their lives, as well as affectively approach their family members.

In this sense, the present study describes an intervention with an adult patient, with cancer, receiving palliative care, using the Dignity Therapy technique as a basis for the intervention. The aim was to evaluate the efficacy of the Dignity Therapy technique, through means of the intervention.

\section{Method}

\section{Design}

This work is characterized by the classical approach of the case study. A case study is a type of scientific investigation that aims to comprehend complex social phenomena and, from this, to explain them, identifying hypotheses and aspects that may be related to the occurrence of these phenomena (Yin, 2015).

The initial proposal anticipated the performance of the intervention with five patients receiving outpatient treatment or hospitalized in a general hospital of high complexity, located in the state of Rio Grande do Sul. This institution is a regional reference health center for the treatment of various medical specialties, among them Oncology. For this, the institution has two exclusive nursing stations. These stations include oncology physicians, a hematology physician, onco-pediatric physicians, nurses, nursing technicians, physical therapists, psychologists, pharmacists, speech therapists, a social worker, a nutritionist and other professionals and health workers. In addition, the institution acts as a teaching hospital, offering medical residencies in Oncology and Multidisciplinary Residencies in Cancer Care.

Although it was proposed as a multiple case study, due to the severity of the clinical manifestations of the studied patients, four of the five patients died before the completion of the intervention. Thus, the study design was adapted to a case report, prioritizing the interventional experience with the single patient that survived the data collection period: from August to October 2015.

The inclusion criteria for this study were: to be over eighteen years of age, to be aware of the prognosis, with no restrictions on gender or race, with expected survival less than or equal to six months, hospitalized or undergoing outpatient treatment during the study period. Patients undergoing curative treatment for cancer, individuals with speech or cognitive disorders and sedated or unconscious patients were unable to participate in the study.

\section{Participant}

The family of Santina (not her real name), 52, was composed of five children: F1 (35 years - male); F2 (33 years - female); F3 (30 years - male); F4 (28 years - male) and F5 (25 years male). She was single for about three years after separating from her second husband. According to the family members, the separation occurred due to the alcoholism of her former husband, the same reason she had separated from her first husband, the father of her children.

The patient worked as a hairdresser before starting the cancer treatment, however, was retired due to disability after years of psychological and psychiatric treatment for Major Depressive Disorder. Santina's appearance corresponded to 
her age. Although emaciated and presenting restrictions regarding her autonomy, she was concerned with her appearance and accredited this vanity to her occupation prior to the diagnosis of Lung Cancer.

Previous History. Santina had been diagnosed with Lung Cancer for approximately two years: she had undergone several rounds of chemotherapy and had been monitored by her oncology physician for some months. During this period, she resumed the use of antidepressant and benzodiazepine medications, as she presented depressive symptoms and insomnia.

During the treatment, the patient lived with three of her children. Initially, she lived with F4 and his wife. However, after a conflict with the stepdaughter, Santina chose to move in with her younger son [F5]. In the period in which she lived with this son, she was involved in conflicts between the eldest son [F1] and the youngest son [F5]. F1 was a drug user and sometimes was welcomed in Santina's house, which bothered F5. On one occasion, after a violent conflict between the two sons, the daughter [F2] invited Santina to live with her, her husband and three children. When the study began, the patient had spent three months in this last house, where she remained until the conclusion of the intervention.

Current Situation. The patient was diagnosed with brain metastasis in September 2015 , approximately two years after the initial diagnosis for Lung Cancer. There were a few weeks where she presented episodes of mental confusion, vomiting and convulsions, which led the family to seek emergency hospital care. The initial intervention period coincided with the diagnosis of the metastasis: at that time, the patient was depressed and apprehensive about the continuity of the treatment and the poor prognosis. Despite only a few years of study, she understood that brain metastasis was a major complicating factor and presented a risk of death. Because of this understanding, Santina put several questions to the health team and the researcher about her clinical condition and her treatment and survival prospects.

\section{Instruments}

To carry out the intervention, the following instruments and techniques were used:

Beck Depression Inventory (Beck \& Steer, 1993a), an instrument that measures the presence and intensity of symptoms of depression. It is composed of 21 items, each with four response statements (with the exception of items 16 and 18 , where there are seven statements, without, however, varying the score) implying increasing degrees of severity of depression, with a score from 0 to 3 . It is composed of items with cognitive-affective and somatic content, such as pessimism, sense of failure, social withdrawal and sadness, among others. The total score classifies the intensity of depression into minimal, mild, moderate and severe levels. Regarding the reliability, the Cronbach's alpha for outpatients was 0.92 , considered a high index.

Beck Anxiety Inventory (Beck \& Steer, 1993b), which is a self-assessment instrument that measures levels of anxiety. This scale is composed of 21 items that are scored from 0 to 3 (zero to three) according to the intensity of the symptoms. The items investigate somatic aspects (such as tremors, tingling, difficulty breathing) and other behavioral aspects (fear of death, terror, inability to relax). The maximum score for the instrument corresponds to 63 points. Regarding the cut-off point to define levels of anxiety, Beck, Epstein, Brown, and Steer (1988) suggest values less than 10 points $=$ no anxiety or minimal anxiety; 10 to 18 points $=$ mild to moderate anxiety; 19 to 29 points $=$ moderate to severe anxiety; and 30 to 63 points $=$ severe anxiety.

Patient Dignity Inventory (Chochinov, Hassard, \& McClement, 2008), an instrument constructed with the aim of measuring various sources of stress related to the dignity of terminally ill patients (how the patients perceive themselves faced with the illness and related suffering). In the reliability analysis of this instrument, Cronbach's alpha coefficient showed an index of 0.93 , indicating excellent internal consistency. The inventory consists of 25 questions covering the sense of dignity of the individuals tested. It 
is considered a self-report type tool, with the ite$\mathrm{ms}$ being scored from 0 to 5 points, according to how much the individual feels the situation suggested by each question causes discomfort or a problem. The higher the score, the greater the suffering of the subject and from a score of 3 the clinical approach of the aspect measured by the question should be considered. The 25 items are constructed from three subscales, which relate to the following factors: concerns associated with illness (8 items), personal dignity (12 items) and social dignity (5 items).

\section{Data Collection Procedure}

The patient was identified by her oncologist as a potential participant and, after referral, was informed about the study and invited to participate. After agreement, the Informed Consent Form (ICF) was signed. Next, the intervention was performed, which consisted of meetings carried out in the hospital: at the bedside, when hospitalized, or in consultation rooms when she was undergoing outpatient procedures. The meetings lasted for approximately one hour each. Although the study predicted only five meetings, another seven meetings were held to complete the intervention and two others at the request of the patient, totaling fourteen meetings. The adjustment in the number of meetings was due to factors related to the worsening of clinical symptoms, the need for surgery and episodes of mental confusion, etc.

In the first moment, an individual interview was performed and the Beck Depression Inventory applied. The next day, the Beck Anxiety Inventory and Patient Dignity Inventory were applied. After the application, the question protocol of the Dignity Therapy was delivered. In this meeting, the first family support was performed, offered to the daughter and eldest son of the patient.

In the third meeting, the patient was performing a surgical procedure for the implantation of an Ommaya reservoir, which would allow intrathecal chemotherapy. After this procedure, the patient took a few days to recover; on the fourth, fifth and sixth days brief visits were made to support her and the family members.
Feeling better and more able to continue, the dignity therapy technique was carried out in the seventh and eighth meetings. These were recorded so that the entire contents could be transcribed, constituting the "legacy" document, delivered to the patient at the end of the intervention. In the ninth meeting, approximately three days after the completion of the Dignity Therapy technique, the patient presented further clinical worsening, accompanied by confusion, and because of this, postponed the review of the document contents, though support for the family members was still provided.

In the tenth meeting, the reading and review of the contents of the "legacy" were performed. The patient chose not to make any changes. Soon after, Santina was discharged and went on to attend the hospital twice a week for completion of the chemotherapy. Thus, in the eleventh meeting the Beck Anxiety and Depression Inventories were reapplied and the "legacy" document was delivered. In the twelfth meeting, the Patient Dignity Inventory was reapplied and support provided for her. In the thirteenth and fourteenth meetings, the patient was anxious and requested the presence of the psychologist researcher, where support was again provided and, three days after the final meeting, she died.

\section{Data Analysis Procedure}

The results of the inventories were considered in their entirety for descriptive purposes, without carrying out any statistical analysis. The intention was only to quantify the efficacy of the Dignity Therapy and not to correlate the psychometric results. In addition, the reports of the meetings were fully transcribed and some excerpts were used for illustrative purposes, aiming to maintain the terms of expression of the patient (in italics).

The meeting transcripts were qualitatively analyzed through the establishment of thematic categories. Categories are a symbolic device to determine significant and recurring themes in the speech of the patient, being, therefore, an abstraction of the researcher. 


\section{Ethical Procedures}

With regard to the ethical issues, this study followed all the procedures set out in Resolution 466/2012 of the National Health Council, receiving authorization for its performance by the Research Ethics Committee of the University of Passo Fundo (CAAE 46168815.1.0000.5342).

\section{Results and Discussion}

As previously mentioned, this is a case study using psychometric and clinical instruments, in order to describe the efficacy of Dignity Therapy with a cancer patient receiving palliative care.

\section{Analysis of the Results Before and After the Intervention}

With the application of the Beck Depression Inventory, during the first meeting, according to the results obtained, the patient presented depressive symptoms (40 points), showing an index of severe depression. However, with the reapplication after the intervention, the sum resulted in 29 points, indicating moderate depression, and therefore, an improvement in the depression level. This result corroborates the literature, which suggests that Dignity Therapy helps, in the short term, to decreased levels of depression and anxiety in patients near the end of life (Julião, Barbosa, Oliveira, Nunes, \& Vaz Carneiro, 2013).

Regarding the measure of anxiety, the results of the Beck Anxiety Inventory indicated, prior to the intervention, the sum of 46 points, this being an index of severe anxiety. After the intervention, the results showed a slight worsening, with a rise to 53 points. This increase in the gross result was probably related to a situation of conflict with the younger son [F5], which took place that day. Furthermore, it was assumed that the confrontation with the end of life, generated by the technique, could also have been associated with the increase in the levels of anxiety.

However, it is believed that these results are not related to a situational crisis, but rather linked to the nature of the technique used, which promotes reflection and revision of values and attitudes adopted throughout life and may cau- se patients to confront potentially painful situations related to the past and the finitude, factors that may favor an increase in anxiety. A case-control study with a Spanish population used two intervention techniques: Dignity Therapy (case group) and Counseling Therapy (control group). The authors found that depression and anxiety levels increased in those who received Dignity Therapy, however, there was also an improvement in resilience; those who received counseling therapy showed improvement in the levels of anxiety and depression and increased resilience. Despite the increase in symptoms such as depression and anxiety, Dignity Therapy was effective for conflict resolution in patients near the end of life (Rudilla, Galiana, Oliver, \& Baker, 2015).

It is known that many of the symptoms assessed by the Beck Anxiety Inventory correspond to physical symptoms, of which the patient presented tremors, tingling, dizziness, difficulty breathing and stomach discomfort. Therefore, the evaluation result may have been skewed by the clinical condition of the patient.

According to the analysis of data related to the correction of the Patient Dignity Inventory, it was identified that in the pre-intervention application the patient presented severe suffering, indicated by the final score of 104 points. Regarding the result of the subscales, it was identified that greater suffering was presented the social factor - 24 points, which equates to $96 \%$. In the post-intervention application, there was an improvement in the sense of dignity, with the final score indicating moderate suffering - 76 points. Again, the greater suffering corresponded to the social factor scale -20 points, $80 \%$. The results obtained from this correction of the Inventory are consistent with the study of Avestan , Rahmani, Heshmati, and Esfahani (2014), which indicated that the most desirable factor for a sense of preserved dignity is the social factor.

\section{Analysis of the Thematic Categories}

The following thematic categories represent the results of the qualitative analysis, it should be emphasized that they were defined according to the potential stressors identified by Chochi- 
nov et al. (2002) - depression, anxiety, desire for death and hopelessness, feelings of futility and worthlessness. In addition to these, other categories were raised from the data collected in the discourse of the patient, such as recommendations, regrets, rewards and efficacy of the therapy. The categories listed above, are discussed in sequence.

\section{Depression}

During the intervention, the patient showed depressive characteristics in her discourse, such as in the following verbalization:

"Today I feel very downcast, because dealing with this situation is not easy, right? To see where all of this is going to lead".

For Nayak et al. (2015), the majority of cancer patients present depressive symptoms, evidenced by signs such as fatigue, sleep disturbances, weight loss, poor appetite, irritability, sadness and nervousness. These symptoms were evident in the patient, who demonstrated emotional suffering due to the illness and the uncertainty regarding the evolution, since the situation that the patient mentions, in this case, corresponds to the clinical worsening and to the brain metastases.

However, it appears that much of her psychosocial distress was associated with conflicts with the children, although the diagnosis may be related to the depressive traits of the patient, which tend to exacerbate the levels of depression and anxiety, as shown in the excerpts below:

On the last day that the [eldest son] messed up, I don't know if he said that he destroyed the house... And then I got very bad! I was destroyed there, do you know what it is to be destroyed? That left me really bad. And then it was the last straw, because then I couldn't give him any more support, he destroyed everything. If there was still a little bit of love, then it went downhill.

I know I cried, cried, cried a lot there. Then the doctor said, 'I'll call the psychologist to talk to you.' I said 'I do not want, let me cry and this will pass, after I cry it'll pass. Then I really cried a lot and it passed.
"Then he [youngest son] did not want me to give him support [oldest son] or him [middle son]. And that made me fell very bad, very bad, you know".

Several studies describe the importance of family and social support during cancer treatment, especially when the patient is receiving palliative care, as it favors psychosocial well-being and improved quality of life. It is suggested that this is due to the assistance advocated by the palliative care, which correspond to the provision of care for physical sufferings, such as reducing pain and helping to perform activities of daily living, as well as the management of psychosocial and spiritual issues (Eom et al., 2013; Pehlivan, Ovayolu, Ovayolu, Sevinc, \& Camci, 2012).

\section{Anxiety}

Signs of anxiety can be observed in the discourse of the patient, related to the fear of clinical worsening or dying:

"I'm afraid of feeling alone, of the sleep, of sleeping and not waking up again".

The patient claimed to feel safer in hospital than when she was at home, as she often did not receive adequate care from her family members in the home. According to Andersson, Burman, and Skär (2011), safety during hospitalization may be associated with good relationships with healthcare professionals, considering that positive interactions can generate, in addition to feelings of security, reduction of anxiety and fear during the hospitalization. Regarding the insomnia and fear of sleep, it is assumed that the patient feared the failure of the family members to act in case of complications, which could result in the death of the patient. According to Melo, Zeni, Costa, and Fava (2013), silence and being alone may lead to increased fantasies related to the fear of sleep and, due to relaxation, to the loss of control over life, being unable to wake up, which explains the frequency of insomnia in patients with serious diseases. Furthermore, it is suggested that there is a correlation between higher levels insomnia and depression (George, Elias, \& Shafiei, 2015). 
It is considered, however, that the effectiveness of palliative care can be enhanced to the extent that the patients remain in their own homes and, thus, enjoy family and social support, when it is appropriate and organized, being able to manage conflicts and sufferings. In this sense, the importance is verified of the home care tea$\mathrm{ms}$, available in order to contribute so that both the patient and family members feel safe when not hospitalized (Milberg et al., 2012).

"Oh, I'm so afraid of... Of half of me dying, you know? I'm afraid of... When those thing that are happening happen, you know? [convulsions]".

In the excerpt above, although not explicitly talking about the fear of dying, the participant comments on the apprehension of losing lucidity, due to the brain metastases. According to Abshire et al. (2015), patients often deny the fear of death when confronted directly, but admit this fear when experiencing any symptoms that, in their perception, could be severe and indicates a risk of death.

\section{Desire for Death and Hopelessness}

No statements related to the desire for death or hopelessness were identified in the recordings. However, in the initial interview and during the pre-intervention application of the Beck Depression Inventory, the participant said: "I'd like to kill myself".

According to Rosenfeld (2014), the desire for early death is a common verbalization among patients facing the end of life. For the authors, this desire may be associated with several variables, such as anxiety and depression derived from the physical symptoms and their severity, as well as hopelessness, spiritual malaise and history of previous treatment for a mental disorder. In order to minimize these reactions, the authors propose that interventions should be performed to reduce the suffering that can be associated with a wish for death.

It is also important to highlight that when the Beck Depression Inventory was re-applied, after the Dignity Therapy intervention, the patient said: "after I started talking to you, I thought no more about it [about committing suici- de]" demonstrating that the technique may have favored her well-being and minimized the desire for death.

It is believed that the hope of patients at the end of life may be related to achievements, such as small clinical improvements or spending more time with family and other loved ones. Hopelessness was associated with losses, such as those of the health, salary and loved ones, as well as despair about the future and death (Olsman, Leget, Duggleby, \& Willems, 2015). It was observed that in the case of the patient in question, the reduction of the desire for early death may have been associated with the intervention, as this favored: proximity of her family members, recovery of positive memories and the ability to be heard regarding her anxieties and suffering.

\section{Feelings of Futility and Worthlessness}

The feeling of worthlessness is a construct that is related to the dignity of terminally ill patients and is characterized by hopelessness and the feeling of abandonment due to the loss of meaning and purpose in life (Robinson, Kissane, Brooker, \& Burney, 2014).

Regarding the feelings of futility and worthlessness, the fear of needing care from the children and, because of that, being a burden to them was identified in some statements. For the patient, to need care from the children was suffering that caused a worsening in her sense of dignity.

"But I feel sorry for them, I'm afraid to bother them [the children]. That's what I'm afraid of, bothering the others".

[My daughter] is my mother, I'm not her mother. It is she who is my mother ... I say so, I call her mother [the daughter], when I'm at home with them [the grandchildren] "the mother is mine". Then they say "the mother is not yours, grandmother, the mother is ours". But I say "the mother is mine too, a little bit mine".

By identifying her daughter as the caring mother, the patient expressed the fragility of her actual clinical condition, showing feelings of worthlessness, since she could no longer exercise the care for herself and her health on her 
own. According to Rapagojal (2010), aspects of how ill individuals are treated, minimizing their suffering and treating them as similar to other patients, "institutionalizing" them in the hospital and uniform them with gowns, lead them to lose their identity, which, for the author, is what dignifies existence. Furthermore, the study also states that many patients at the end of life desire to be listened to with attention, so they can be treated considering their singularities, which reflects the relevance of psychologists in the palliative care teams.

\section{Recommendations}

According to what is proposed by various questions of the Dignity Therapy protocol, much of the dialogue of the patient was focused on recommendations for their family members, forming a farewell document.

I want, I want them [the children] to remember this: that they do not fight about money, they do not fight because of material goods, because this doesn't take us anywhere. We are not happy with material possessions. Only this, I hope that they think when I'm no longer here, that they remember that their mother did not want this for them, their mother did not want them to fight with each other, you know?

"I want him [the grandson] to go in the army. For him to get an education, learn good things". I want to tell them [the children] I do not want them to quarrel, I want them to live well, that in their minds I will last for the rest of the life. I want them to stay with that memory, that we go through here, we do not live here. We're passing through. We have to live the moments well, a few moments, but live well.

The recommendations of the patient are the legacy she left for her family members as an extension of herself into the future. To advise on how and what should be done brings a sense of autonomy and recovery of control over life itself, since it gives voice and importance to the individual in the terminal process, who loses, throughout the illness, several social and fami- ly roles (Baker, Armour, Meystre, Redwood, $\&$ Dawson, 2015). It was identified that, for the patient, the technique allowed her to recover her autonomy through the verbalization of what she wanted and what she recommended for her children and grandchildren. This was possible due to what is believed to be the most important function of the psychologist in the palliative care team: to provide sensitive listening to the person that presents suffering, so that the identification of feelings and emotions is enabled, favoring the therapeutic effect of the dialogue (Coelho \& Ferreira, 2015).

\section{Regrets}

It can be seen that the Dignity Therapy technique provides patients with the possibility through the revision of attitudes and behaviors of the past - to evaluate and resume pending issues, which enables them, if necessary, to repent and ask forgiveness for situations for which they feel guilt. This aspect was locate in the following fragments:

I regret that I could not have helped my daughter more, as she helped me so much, and raised my children. While I worked at night, she took care of them. And I could not return this, do what she did for me. I would just like to have a little more life so I could look after one of her children a little more, to fix what I didn't do.

Maybe things that I didn't do for my mother, for my brothers, things that I didn't do for them. When I go to church I always ask forgiveness, you know? But anyway, I feel inside of me that there is something I still have to ask forgiveness for. And I pray for them [the children] with all my heart, I've asked five hundred times.

I ask forgiveness for something that I did not do well in life, that I should have done, right? Maybe because I left their father [first husband, father of the children], I ask forgiveness. I was not happy with him, but maybe they can criticize me because I left him.

While recognizing that she was near the end of her life, the patient talked about the desire 
to live more to repair situations in which she had regrets, showing affection for her children and desire to be forgiven for something she believed had harmed them. Thus, it is understood that an appropriate intervention, in this case, would be to facilitate the reparation and proximity between the patient and family members, allowing the bonds of affection to serve as promoters of dignity and a good death (Paulo, 2013). In this context, it should be noted that among the psychological intervention possibilities in palliative care and end of life, it has taken into account that the life review process, made possible through techniques such as Dignity Therapy, can encompass proposals of regret, guilt and reparation (Kemp, 2006).

\section{Rewards}

It was found that in many statements the patient referred to the rewards and gratifications that she had during her life. For her, remember raising her children and, thus, the legacy she left them, made her feel happy and proud, as can be identified in the following excerpts:

What made me feel happiest was I got my lunch and my bosses said "aren't you going to eat, Santina?" "No, I won't eat, I will take it for the children". "But you earn the money to buy your food". "No, this I take for them to eat, the other one is for tomorrow morning, for them to have breakfast". So I felt so good when I got a small piece of bread, even if it was a dry crust, but I had to give it to them to eat.

"Until now I managed to live well. I love them [the children], every little bit of them, each one of them. Everything I went through".

"Look, even with everything, everything, everything, to have two drug addict children, even with everything, I still am proud of my children. I am still proud of them. It is my greatest pride".

"I had to play various roles. And considering all the roles that I have played, I fulfilled them more or less, because there were many".

To recognize having played important roles and performed these satisfactorily, is a way of acknowledging that she fulfilled the purposes for her life, which favored, for the patient, the process of farewell and acceptance of the end of life. According to Moraes, Almeida, and Cunha (2015), death from a chronic condition allows patients to acknowledge their regrets, unlike what occurs with sudden deaths. It is understood, therefore, that patients in palliative care have a chance to reconstruct and repair relationships in the end of life period, as was the case for the patient of the study.

\section{Efficacy of the Therapy}

In addition to the data on decreased levels of depression, improved sense of dignity and increased anxiety, fragments of the discourse were found that referred to satisfaction with the technique, where its possible efficacy appeared.

What I'm doing here no one forced me to do. She [researcher] told me and I accepted, because it's something I think I'll feel good about and I'll die in peace. I'll have peace. If I don't do this I won't have peace.

The feeling that the intervention would promote improvement in her quality of life and also lead to a good quality of death was identified in the statements of the participant. This was due to the technique helping in the resolution of some conflicts, in the proximity with her children, in the possibility to carrying out recommendations she considered important to the lives of those she loved and in the recognition of the difficulties and achievements that had accumulated in her life story.

So, if I do this, if I die tomorrow, dead at dawn tomorrow, I'll be at peace, I'll be okay with myself. Or I'll say, tomorrow after I die I'm not feeling heavy, I won't have a heavy conscience. I'm at peace because I did what I wanted to do.

Regarding the possibility of providing quality of death, Monstross-Thomas et al. (2015) point out that Dignity Therapy is seen by patients, family members and members of the health team as valid and effective, given that the technique reduces anxiety, promotes feelings of contentment, gratitude, hope and resilience, recovers the significance of life and constitutes 
as a way to resolve conflicts and create an atmosphere of connection with other people.

\section{Final Considerations}

Upon completion of the intervention with the Dignity Therapy technique and pre- and post-intervention measurement with the Beck Anxiety and Depression Inventories and the $\mathrm{Pa}$ tient Dignity Inventory, it can be inferred that the patient showed improvement in levels of depression and the sense of dignity, indicating the efficacy of therapy. However, there was an increase in the level of anxiety, a result that may have been skewed by conflicts that the patient had with family members and a natural response faced with the review of conflicts, attitudes and behaviors experienced throughout life, before the reapplication of the Beck Anxiety Inventory.

Although there are no results from psychometric tests that could support this assumption, it is believed that the patient had personality characteristics that favored the positive result because she was a flexible, generous and affectionate person, who accepted suggestions that facilitated interpersonal relationships and realized the intervention was an opportunity for growth, which can be identified through the valorization of the meetings and the request for them to be extended after the completion of the technique.

It should be noted that, although the work was made in a multiple case study format, only one of the five patients addressed was able to complete the intervention, as the others presented clinical complications or death during the study, making it impossible to complete the intervention. Given that the start date of the intervention was in August 2015 and completion in October 2015, it was observed that these patients rapidly evolved to the final outcome (days, weeks, or two months after the start of the intervention). This is justified by the lack of specialist palliative care staff in the institution, resulting in the late referral of severely ill patients to palliative care, even those in the end of life process. Although patients facing terminality follow the monitoring with the multidisciplinary oncology team, the treatments they are offered are similar to those offered to patients with a perspective of cure.

It is also understood that the restriction of the study to a single case occurred because of the oncology team's difficulty in identifying and referring, among their patients, those at the end of life - possible subjects for this study. This highlights that a team with specific training for palliative care could detect and treat, with technical clarity, individuals affected by serious illnesses, avoiding their exposure to unnecessary procedures, treatments and suffering.

Finally, it is suggested that, although the study has shown that the Dignity Therapy technique can benefit patients receiving palliative care, other studies should be carried out with the Brazilian population, aiming for an evaluation of the technical feasibility, relating the efficacy of the therapy to personality factors of patients, among other factors.

\section{References}

Abshire, M., Xu, J., Himmelfarb, C. D., Davidson, P., Sulmasy, D., Kub, J., ...Nolan, M. (2015). Symptoms and fear in heart failure patients approaching end of life: a mixed methods study. Journal of Clinical Nursing, 24(21-22), 32153223. doi:10.1111/jocn.12973

Andersson, L., Burman, M., \& Skär, L. (2011). Experiences of caretime during hospitalization in a medical ward: older patients' perspective. Scandinavian Journal of Caring Sciences, 25(4), 646-652. doi:10.1111/j.1471-6712.2011.00874.x

Araújo, L. Z. S., Araújo, C. Z. S., Souto, A. K. B. A., \& Oliveira, M. S. (2009). Cuidador principal de paciente oncológico fora de possibilidade de cura, repercussões deste encargo. Revista Brasileira de Enfermagem, 62(1), 32-37. doi:10.1590/S0034-71672009000100005

Araújo, M. M. T., \& Silva, M. J. P. (2012). Estratégias de comunicação utilizadas por profissionais de saúde na atenção a pacientes sob cuidados paliativos. Revista da Escola de Enfermagem da USP, 46(3), 626-632. doi:10.1590/S008062342012000300014

Avestan, Z., Rahmani, A., Heshmati, F., \& Esfahani, A. (2014). Perceptions of Iranian cancer patients regarding respecting their dignity in hospital 
settings. Asian Pacific Journal of Cancer Prevention, 16(13), 5453-5458. doi:10.7314/ APJCP.2015.16.13.5453

Baker, N., Armour, K., Meystre, C., Redwood, S., \& Dawson, A. (2015). PA14 The legacy of cancer: Why a health promoting approach is so important in palliative care. BMJ Supportive and Palliative Care, 5(Suppl. 1), A23-A24. doi:10.1136/bmjspcare-2015-000906.74

Beck, A. T., Epstein, N., Brown, G., \& Steer, R. A. (1988). An inventory for measuring clinical anxiety: Psychometric properties. Journal of Consulting and Clinical Psychology, 56(6), 893897. doi:10.1037/0022-006X.56.6.893

Beck, A. T. \& Steer, R. A. (1993a). Beck Depression Inventory - Manual. San Antonio, TX: Psychological Corporation.

Beck, A. T., \& Steer, R. A. (1993b). Beck Anxiety Inventory - Manual. San Antonio, TX: Psychological Corporation.

Chochinov. H. M. (2007). Dignity and the essence of medicine: The A, B, C, and D of dignity conserving care. $B M J, 335(7612), 184-187$. doi:10.1136/bmj.39244.650926.47

Chochinov, H. M., Hack, T., Hassard, T., Kristjanson, L. J., McClement, S., \& Harlos, M. (2002). Dignity in the terminally ill: A cross-sectional, cohort study. The Lancet, 360(9350), 20262030. doi:10.1016/S0140-6736(02)12022-8

Chochinov, H. M., Hack, T., Hassard, T., Kristjanson, L. J., McClement, S., \& Harlos, M. (2005). Dignity therapy: A novel psychotherapeutic intervention for patients near the end of life. Journal of Clinical Oncology, 23(24). doi:10.1200/JCO.2005.08.391

Chochinov, H. M., Hassard, T., \& McClement, S. (2008). The Patient Dignity Inventory: A novel way of measuring dignity-related distress in palliative care. Journal of Pain and Symptom Manage, 36, 559-571. doi:10.1016/j. jpainsymman.2007.12.018

Coelho, M. E. M., \& Ferreira, A. C. (2015). Cuidados paliativos: Narrativas do sofrimento na escuta do outro. Revista Bioética, 23(2), 340-348. doi:10.1590/1983-80422015232073

Eom, C. S., Shin, D. W., Kim, S. Y., Yang, H. K., Jo, H. S., Kweon, S. S., ...Park, J. H. (2013). Impact of perceived social support on the mental health and health-related quality of life in cancer patients: Results from a nationwide, multicenter survey in South Korea. Psychooncology, 22(6), 1283-1290. doi:10.1002/pon.3133

Fitchett, G., Emmanuel, L., Handzo, G., Boyken, L., \& Wilie, D. J. (2015). Care of the human spirit and the role of dignity therapy: A systematic review of dignity therapy research. $B M C$ Palliative Care, 14, 8. doi:10.1186/s12904-0150007-1

George, M., Elias, A., \& Shafiei, M. (2015). Insomnia in Cancer - Associations and implications. Asian Pacific Journal of Cancer Prevention, 16(15), 6711-6714. doi:10.7314/ APJCP.2015.16.15.6711

Julião, M. (2014). Eficácia da Terapia da Dignidade no sofrimento psicossocial de doentes em fim de vida seguidos em cuidados paliativos: Ensaio Clínico Aleatorizado e Controlado (Unpublished doctoral dissertation, Universidade de Lisboa, Portugal).

Julião, M., Barbosa, A., Oliveira, F., Nunes, B., \& Vaz Carneiro, A. (2013). Efficacy of dignity therapy for depression and anxiety in terminally ill patients: Early results of a randomized controlled trial. Palliative and Supportive Care, 11(6), 481489. doi:10.1017/S1478951512000892

Kemp, C. (2006). Spiritual care interventions. In B. R. Ferrel \& N. Coyle, Textbook of Palliative Nursing (pp. 595-604). New York: Oxford.

Melo, A. C. de, Valero, F. F., \& Menezes, M. (2013). A intervenção psicológica em cuidados paliativos. Psicologia, Saúde e Doenças 14(3), 452-469. Recuperado em http://www.scielo. mec.pt/scielo.php?script $=$ sci_arttext\&pid $=$ S1645-00862013000300007

Melo, A. F. V. de, Zeni, L. L., Costa, C. L. da, \& Fava, A. S. (2013). A importância do acompanhamento psicológico no processo de aceitação de morte. Estudos e Pesquisas em Psicologia, 13(1), 152166. Recuperado em http://pepsic.bvsalud.org/ scielo.php? script=sci_arttext\&pid=S180842812013000100010\&lng $=\mathrm{pt \&}$ tlng $=\mathrm{pt}$

Milberg, A., Wåhlberg, R., Jakobsson, M., Olsson, E. C., Olsson, M., \& Friedrichsen, M. (2012). What is a 'secure base' when death is approaching? A study applying attachment theory to adult patients' and family members' experiences of palliative home care. Psychooncology, 21(8), 886-895. doi:10.1002/pon.1982 
Montross-Thomas, L. P., Irwin, S. A., Meier, E. A., Gallegos, J. V., Golshan, S., Roeland, E., ...Rodseth, L. (2015). Enhancing legacy in palliative care: study protocol for a randomized controlled trial of Dignity Therapy focused on positive outcomes. BMC Palliative Care, 14, 44. doi:10.1186/s12904-015-0041-z

Moraes, M. S., Almeida, F. A., \& Cunha, M. L. R. (2015, 5-7 ago.). Percepções do enfermeiros em relação ao processo de morte e luto na unidade de terapia intensiva neonatal. In Atas Congresso Ibero-Americano em Investigação Qualitativa (pp. 426-431). Aracaju, SE, Brasil.

Nayak, M. G., Vidyasagar, M. S., Nayak, S., Nayak, B. S, Shashidhara, Y. N., \& Kamath, A. (2015). Symptoms experienced by cancer patients and barriers to symptom management. Indian Journal of Palliative Care, 21(3), 349-354. doi:10.4103/0973-1075.164893

Olsman, E., Leget, C., Duggleby, W., \& Willems, D. (2015). A singing choir: Understanding the dynamics of hope, hopelessness, and despair in palliative care patients. A longitudinal qualitative study. Palliative and Supportive Care, 13(6), 1643-1650. doi:10.1017/S147895151500019X

Paulo, A. C. M. (2013). A solidão em doentes oncológicos em fase terminal: Um estudo de caso (Master's thesis, Universidade Católica Portuguesa, Portugal).

Pehlivan, S., Ovayolu, O., Ovayolu, N., Sevinc, A., \& Camci, C. (2012). Relationship between hopelessness, loneliness, and perceived social support from family in Turkish patients with cancer. Supportive Care in Cancer, 20(4), 733739. doi:10.1007/s00520-011-1137-5

Rapagojal, M. R. (2010). Disease, dignity and palliative care. Indian Journal of Palliative Care, 16(2), 59-60. doi:10.4103/0973-1075.68400
Robinson, S., Kissane, D. W., Brooker, J., \& Burney, S. (2014). A review of the construct of demoralization: History, definitions, and future directions for palliative care. American Journal of Hospice and Palliative Medicine. doi:10.1177/1049909114553461

Rosenfeld, B. (2014). Does desire for hastened death change in terminally ill cancer patients?. Social Science and Medicine, 111, 35-40. doi:10.1016/j. socscimed.2014.03.027

Rudilla, D., Galiana, L., Oliver, A., \& Barreto, P. (2015, Oct 14). Comparing counseling and dignity therapies in home care patients: A pilot study. Palliative and Supportive Care, 1-9. doi:10.1017/S1478951515001182

World Health Organization. (1990). Cancer pain relief and palliative care report. Genebra: Author.

World Health Organization. (2002). National Cancer Control Programmes: Policies and Managerial Guidelines ( $2^{\text {nd }}$ ed.). Genebra: Author.

Yin, R. K. (2015). Estudo de Caso: Planejamento e métodos $\left(5^{\text {th }}\right.$ ed.). Porto Alegre, RS: Bookman.
Recebido: 04/01/2016

$1^{a}$ revisão: 11/04/2016

$2^{a}$ revisão: $25 / 04 / 2016$

Aceite final: 26/04/2016 